\title{
Knowledge Management as a Competitive Advantage to the Brazilian MVAS Ecosystem
}

\author{
Rosângela Spagnol Fedoce', Renato de Oliveira Moraes², José Roberto Castilho Piqueira ${ }^{3}$
}

\begin{abstract}
The mobile value added service (MVAS) is a method of differentiation in the mobile telephone market and represents approximately $30 \%$ of the mobile network operator (MNO)'s revenue. The Brazilian MVAS sector consists of the content provider, the MNO, and the integrator. This paper aims to examine this sector by analyzing two main stakeholders: the MNOs and the integrator. We conducted a case study in the main Brazilian integrator and administered a questionnaire to managers/consultants of four MNOs that represent $74.1 \%$ of the national market share. The results indicate that the integrator has developed knowledge management, intellectual capital and competitive intelligence, operating as a business enabler and creating competitive advantage for this sector. The analysis of the collected data has been more relevant than the capacity of the integration platform. These collaborative relationships have consolidated this market as an ecosystem that operates according to the concept of coopetition.
\end{abstract}

Keywords: mobile value added service (MVAS); knowledge management; competitive intelligence; intellectual capital; coopetition.

\footnotetext{
1,3Escola Politécnica da Universidade de São Paulo, Departamento de Engenharia de Telecomunicações e Controle, Avenida Prof. Luciano Gualberto, travessa 3-I58, 05508-900 São Paulo-SP, Brazil. 3Phone number: 55 II 309I-522I, e-mail: piqueira@lac.usp.br Phone number: 55 II 97994-3622 / 55 II 309I-I737, e-mail: rosangela.fedoce@usp.br

${ }^{2}$ Escola Politécnica da Universidade de São Paulo, Departamento de Engenharia de Produção,Avenida Prof. Luciano Gualberto, 530, 05508900 São Paulo-SP, Brazil. Phone number: 55 II 309I-522I, e-mail: renato.moraes@poli.usp.br
} 


\section{Introduction}

The mobile telephone market has been increasing all over the world, connecting people and changing according to the technological dynamism. There are 3.4 billion unique subscribers, which represents a $47 \%$ penetration. Globally, $3 \mathrm{G}$ connections have approximately quadrupled since 2008 to two billion in 2013 (GSMA Intelligence, 2014).

Latin America accounts for 10\% of the global mobile telephone market in terms of revenue. This market is now moving to a new phase of development characterized by increasing market maturity and by slowing revenue and subscriber growth. However, significant growth remains, driven by new services and applications and by the increase of mobile broadband access (GSMA and BCG, 20I3).

Smartphones are becoming more accessible to middle and lower income groups in this region because of increasing availability of lower cost models (Bibolini and Lancaster, 2014). Brazil, which is our study focus, is the first mobile network market in this region, and the fifth in the world, with a density of 1.38 cell phones per inhabitant (Teleco, 20I5).

Despite mobile subscriber growth and increased mobile broadband access, the average revenue per user (ARPU), calculated by dividing the net service revenue by the average number of cell phones, has globally declined. This result indicates that the average tariff prices for mobile network operators (MNOs) have been decreasing due to competition, the possibility of access at lower price points, the growth of multi-devices, etc.

MNOs have invested in mobile value added service (MVAS) to gain differentiation in this market. MVAS adds value to the standard telecommunications offering, encouraging subscribers to increase the use of their phone and allowing the MNO to enhance its ARPU (Frattini, Dell'Era and Rangone, 20I3). The data revenue related to services has been considerable to liquid revenue of the main 3G MNOs. In 2014, the percentages were $69 \%$ in SoftBank (Japan), $57.6 \%$ in Verizon (United States), and 38.6\% in Vivo (Brazil) (Teleco, 2015).

MVASs add new utilities related to access, storage, presentation, movement or information retrieval to a telecommunication service (LGT 9472/97). Teleco (2015) highlights three main components: short message service (SMS), multimedia messaging service (MMS), and Internet access (data packages), in addition to services such as messaging, entertainment, social networks, payments, and location based services.
According to GSMA et al. (20I2), the key stakeholders of the MVAS sector are MNOs, over-the-top players (OTTPs), handset manufacturers, international foundations, content developers, and local partners. Figure I shows that the relationships in this sector often underscore interdependencies between different actors in developing and presenting different MVASs to the market.

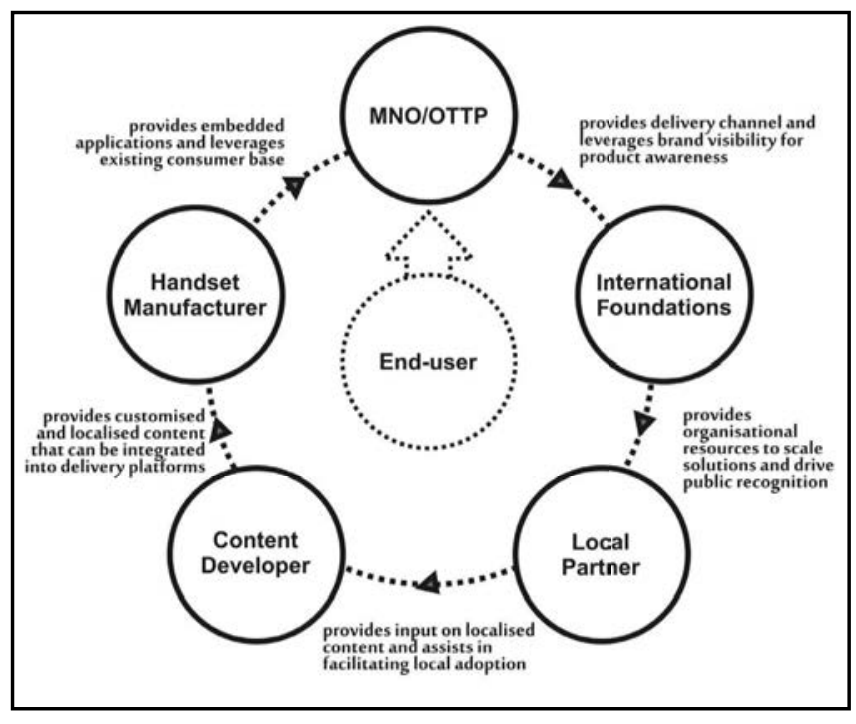

Figure I.The MVAS ecosystem standard. Source: GSMA mWomen et al. (2012).

In the Brazilian MVAS sector, the key stakeholders are the content provider, MNO, and integrator. Service integration is a potentially multifaceted role that includes different business models, such as setting up a mobile portal, aggregating content from various sources, and customizing service packages for different market segments (Mylonopoulos and Sideris, 2006). In Brazil, the integrator provides support and technology for the use of the operating platform, including telephones as a media channel (Pure, 20I2). Its main role is to provide technology services to content providers so that they can spread and monetize their contents.

In this market (Figure 2), the provider supplies content to be integrated by the integrator. The integrator then provides the technology that is disseminated by the MNO, which then reaches the end user, generating trades for the whole chain. The content provider can also present a project directly to the MNO, which sends the project to the integrator.The National Telecommunication Agency (Anatel) regulates the relationship between $M N O$ and end user, and published rules about MVAS in 20I0. In addition to Anatel, there are self-regulated associations, such as the Mobile Entertainment Forum (MEF), that developed a conduct code with procedures for mobile services and publicity. 


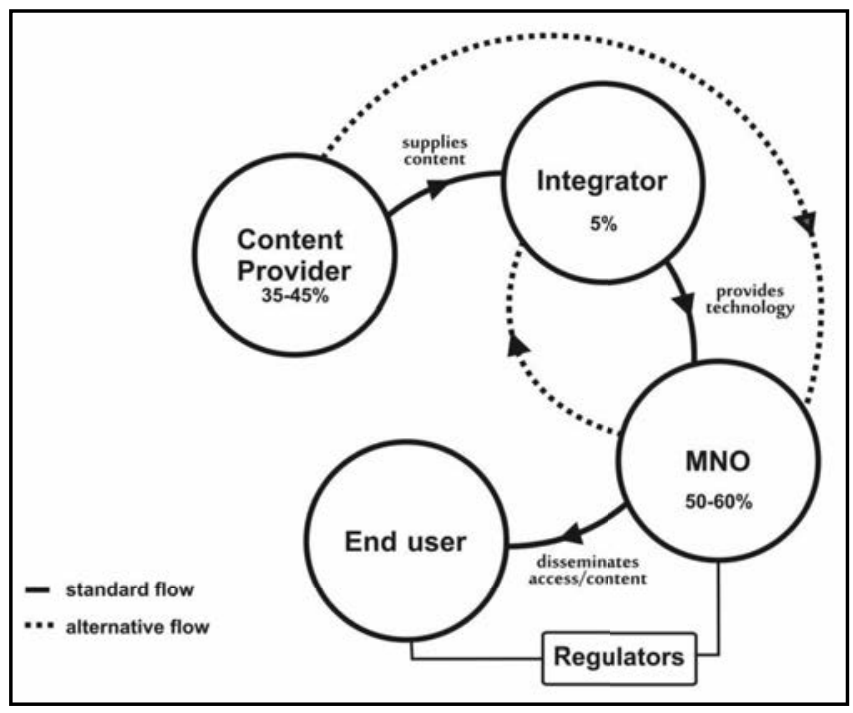

Figure 2.The MVAS sector in Brazil.The percentages indicate the approximate billing of each stakeholder.

In addition to the recent regulation, the expansion of smartphone and tablet sales has transformed this market. With access to mobile Internet came the introduction of the app stores, expanding the possibilities of producing and of distributing contents to companies, such as Google and Apple, as well as to autonomous developers and MNOs. The MNOs have been the propeller engine of this market, but the business models are changing due to the entrance of new actors, which is directly related to technological convergence (Silveira, 2008).

In this converging environment, users can acquire information and entertainment services in addition to high quality data and voice services (Tan and Zeng, 2009). Therefore, traditional revenues (voice and messaging) for the MNOs have been affected by new online messaging services, such as WhatsApp and Skype, increasing the pressure to diversify their revenue streams (GSMA Intelligence, 20I4).

In addition to the diffusion of devices with Internet connection, Fries (20II) also observed a risk of direct connection between content provider and MNO that threatens the integrator's role. He noted that integrators must invest in more efficient reports and analyses in professional qualification and service delivery with differentials to remain competitive.

Therefore, the same dynamism that has restructured the mobile telephone market, and particularly the Brazilian market, has also presented potential risks to the current MVAS sector, as it can modify the role of some segments as well as the productive and distributing flow of content and access.
Within this context, this study aims to examine the dynamism of the Brazilian MVAS sector, through an analysis of its main stakeholders: the integrator and the MNOs. We intend to analyze how an integrator has invested in solutions to add value to their services and create a potential competitive advantage to this dynamic sector, with a focus on knowledge management (KM), intellectual capital (IC) and competitive intelligence $(\mathrm{Cl})$. To complement this approach, we will analyze the viewpoint of representatives of four MNOs. We choose an integrator responsible for approximately $90 \%$ of the national integrations, and MNOs that represent $74.1 \%$ of the national market share. We prefer to study MNOs instead of content providers because MNOs are responsible for the transmission of mobile content through cell phones. This paper is organized into eight sections. Section $I$ is the introduction. Section 2 reviews the literature. Section 3 describes the research method. Section 4 provides results. Section 5 is a discussion based on the theoretical framework. Section 6 concludes the paper with an overview of our contributions and the limitations of the study. Section 7 contains the acknowledgements, and Section 8 lists the references.

\section{Literature review}

In this dynamic market, $\mathrm{Cl}, \mathrm{KM}$ systems and IC have been relevant to understand the end users' demands and to diversify services. $\mathrm{Cl}$ involves environmental scanning and detailed analyses regarding market behavior. From the strategy input selection, strategic information can be collected with environmental scanning, which is related to acquisition and use of information about events, trends, and relationships in the external environment, resulting in knowledge that companies can use to plan future actions (Choo, 1999). Due to constant technological improvement and the emergence of new resources and functionalities that modify the tools for data mining as well as the customer needs, continuous organizational learning is also essential for $\mathrm{Cl}$.

Kahaner (1996) stated that $\mathrm{Cl}$ is a systematic program for gathering and analyzing information about one's competitors' activities and general business trends to further one's own company's goals. Intelligence helps a company sustain and develop distinct competitive advantages by using the entire organization and its networks to develop actionable insights about the environment, including customers, competitors, regulators, technology, and others (Calof, 2008). The knowledge generated in the process of $\mathrm{Cl}$ needs to be transferred to the organization, promoting a culture focused on KM (Machado, Abreu and Neto, 2013).

Erickson and Rothberg (2009) stated that KM tends to be oriented to human resources, including Information 
Technology (IT) systems to collect, store, and distribute codified knowledge. Organization knowledge creation must amplify the knowledge created by individuals and crystallizes the data at the group level through dialogue, discussion, experience sharing, and community of practice (Takeuchi and Nonaka, 2008).

IC is related to intangible assets and involves human capital (skills, training, and experience), structural capital (IT systems, and corporative culture), and relational capital (internal knowledge about external sectors, such as customers and suppliers). According to Stewart (200I), IC is the knowledge that transforms raw materials and makes them more valuable. He explained how companies that use knowledge assets can deftly eliminate the expense and burden of carrying physical assets, or maximize their return on those assets.

Both $\mathrm{Cl}$ and $\mathrm{KM}$ programs can benefit from business intelligence $(\mathrm{BI})$ tools improving the competitiveness in the market. BI analytical capability helps knowledge workers in the development of strategic opportunities, in the investigation of problematic areas in the business, and in decision-making (Heinrichs and Lim, 2003, 2005).

The investment in technology and in the promotion of KM, $\mathrm{IC}$, and $\mathrm{Cl}$ can be a way for the MVAS sector to survive and to innovate in this dynamic market, allowing for competition and collaboration at the same time.According to Luo (2004), coopetition is a new strategy that uses the conventional rules of competition and cooperation to combine the advantages of competitors. To Gueguen and Isckia (200I), coopetition builds on the idea that competitors should not just be considered rivals for market dominance but also valuable sources of innovation.

\section{Methodology}

From the theoretical framework, we developed a single case study in the main Brazilian integrator and administered a questionnaire in 2012 and 2013 to managers/consultants of four MNOs. The development of a single case study, and not of a multiple case study, is due to the representativeness of the studied integrator (Yin, 2005). This integrator is responsible for approximately $90 \%$ integrations and hired by all the MNOs in Brazil, with branch offices in Italy, Mexico, and Central America. Therefore, the lessons learned in this case can provide information about the integrator's role in this market.

We used a protocol to conduct the case study that included the study's general procedures, the field procedures, the study issues and the guidelines for preparing the final report (Yin, 2005). The field procedures used were semistructured interviews conducted from an agenda (guideline) with questions that aimed to understand the meanings that interviewees assign to issues and situations related to the studied topics (Godoy, 2006). The interviews were administered to the Chief Executive Officer (CEO) and the commercial and operational managers that signed a consent form authorizing the use of their information in this paper.

We also administered questionnaires to the managers and consultants of four of the main MNOs in Brazil that have the business of more than $88 \%$ of the covered population. The respondents were a planning control manager in network operations, a VAS marketing consultant, a VAS marketing manager, and a network-planning manager. They consented to the use of their information provided that their name and their companies were not identified.

The analysis of the interviews' answers of the case study and the open questions of the questionnaire used a categorization of the information. The categories are derived from the theoretical framework and are consolidated in the agenda of semi-structured questions (Duarte, 2005). The analysis categories were $\mathrm{KM}, \mathrm{IC}$, and $\mathrm{Cl}$. After this categorization, an interpretive analysis was performed. The interpretive analysis is different from the content analysis due to its focus on the information itself, instead of on the language or the quantification of words.

\section{Results}

The results showed the studied integrator created a market standard and participated in the regulation of the standard as a partner of the MNOs. The integrator operates with subscription models or downloads, interactivity, mobile marketing and Wireless Application Protocol (WAP) billing. Its main services are voting by SMS, teletext, pincode, quizz, broadcast, games, videos, channels of contents, and mobile marketing campaign management.

The integrator operates with revenue share contracts and business-to-business (B2B) contracts. It integrates contents for MNOs, but does not provide service sales directly to end users. The integrator has a commercial sector working in contact with MNOs and content providers to develop new businesses. Its customer relationship department intermediates the communication with these entities regarding technical support and mobile projects, such as developing technologies that enable the entities to send SMS to TV programs, and to configure mobile devices for receiving social network updates.

The integrator has invested in a Data Warehouse for $\mathrm{BI}$ activities, which helps in data storage, environmental scanning, and KM. Internal and external scanning are conducted daily through informal talks, information generated by 
platforms, and market research. The scanning aims to meet the integrator's own challenges, with improvements in management through the analyses of the partners' complaints. Research is conducted on foreign and national companies that developed solutions that can add value to the integrator's services, generating $\mathrm{Cl}$.

BI platforms have mostly been developed by the integrator's IT team to create reports with information needed by MVAS business, such as the global revenue of this sector per type of service, per MNO, and per content provider.The operational manager stated that analyses processed by the platform are still basic, and simple data are generated. These data include a comparison between the number of prepaid and postpaid consumers that hired a service.

The platform generates between 20 and 30 million records a day, and analysis is necessary to turn the records into strategic knowledge for partners. The integrator has a revenue assurance sector that continuously scans the services, customer-by-customer, generating results that compare each day with results of previous days. The partners receive not only primary data but also complete analyses based on $\mathrm{BI}$ tools and the expertise of the strategic team. For example, the integrator produces monthly analyses to content providers, showing billing data, user base behavior, need of investment in media campaign, and information about traffic profile (prepaid and postpaid users, main day to charge, main place to offer a service, among others).

Based on this information, the integrator creates market behavior indices, and when the results do not fit the standard, the system emits an alert. When the integrator identifies changes in the traffic of a content provider, the changes are immediately reported, due to the urgency of this information. The integrator also does consulting work to guide partners or future partners concerning the feasibility of their projects in the MVAS sector.

Therefore, the integrator has invested in IC in addition to developing platforms for integration. According to the interviewees, the integrator actually operates with more emphasis on the human and relational capital than on the structural capital. The analyses of data collected by BI tools and the good relationship with MNOs and content providers have been more relevant than the very capacity of the integration platform.

In addition, the integrator has worked to turn its IT team into a more proactive one, promoting improvements in the communication between its teams as well as with MNOs and content providers. It has also developed organizational learning concerning the integration platform and the MVAS sector. These investments show the importance of a good relationship with partners, in addition to developing better technologies.

Three of the four MNO respondents corroborated the collaborative relation in the MVAS sector. One of the MNOs does not notice strategic information exchange, except in the contractual case of confidentiality because this market is competitive and the ideas/implementation time are determinant factors. Others agree that there is a strategic information exchange related mainly to the business management, such as interesting rates for specific services, better days to tariff the end user, experiences about services that were already created, and others.

According to MNO respondents the main MVAS consumed in Brazil, in priority order, are SMS, music, ringtones, mobile broadband, games, mobile publicity, MMS, videos, and mobile payment. Regarding the main differences between the national and international mobile telephone market, some respondents noted that the integrator's role is more common in Latin America. An MNO manager stated that in Spain and in Portugal, for instance, companies with a focus on integration are rare, while companies that operate with content development and aggregation jointly with integration are more common.

The MNO respondents highlighted that the integrator's role has been threatened by the possibility of direct connections between content providers and MNOs. The respondents suggested that integrators should provide business opportunities and improve the value chain. They listed the most important types of information given by the integrator to their business. Figure 3 shows that the main types of information are linked with billing and improvement in services.

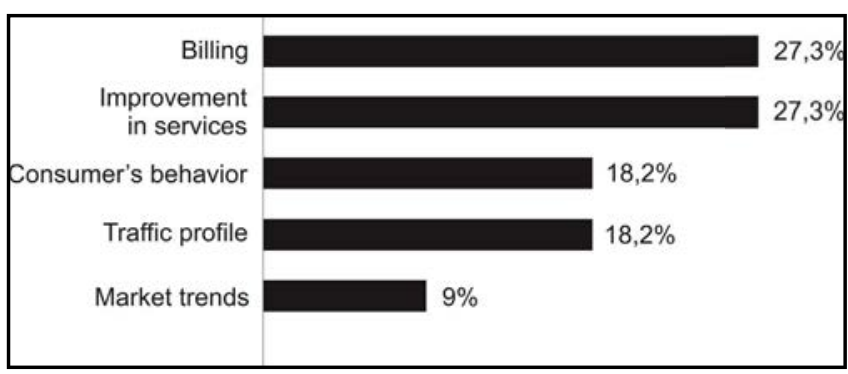

Figure 3. Main types of information given by the integrator to MNOs.

The MNO respondents explained that their companies have invested in $\mathrm{Bl}$ and $\mathrm{Cl}$, developing searches and hiring consultants to analyze market trends and consumers' needs. They enumerated five strategic inputs defined by Fahey 
(2007) according to their companies' priority. These inputs included marketplace opportunities, competitive risks, key vulnerabilities, core assumptions, and competitor threats.

Most of the MNO respondents noted that the impact of devices with Internet connections and app stores in their businesses and in the mobile telephone market chain represents a possibility for new partnerships and services, as depicted in Figure 4. A respondent highlighted that new devices represent a risk or an opportunity for $\mathrm{MNO}$ business and for the companies of the productive flow, depending on the service offered. For some MNOs that offer Internet access, for instance, new devices could be an opportunity.

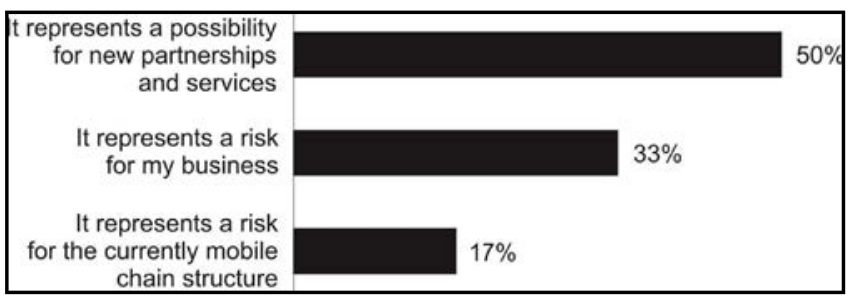

Figure 4. What the devices with Internet connection and the app stores represent to MNO business and to the Brazilian MVAS sector.

Regarding app stores, some respondents stated that they imply the decrease of MVAS end users, but expand mobile Internet access, and consequently expand the sales of Internet plans by MNOs. A respondent noted that Google Play represents an opportunity, while the Apple Store has been a risk. He explained that Android apps are free and that MNOs have control of the billing, while Apple has the highest revenue.

The competition from MNOs with mobile virtual network operators (MVNOs) and OTTPs was also mentioned as a challenge because it reduces the price of voice, SMS, and Internet plans, creating demand for increased network capacity. For instance, the MVNOs use the MNOs' networks and their focus lies on specific market segments, such as corporate and university. The OTTPs use the MNOs' networks to offer competitive services such as SMS, but they are neither charged the same tax nor regulated with the same laws as MNOs are.

\section{Discussion}

The integrator has developed $\mathrm{KM}$ and $\mathrm{Cl}$ based on its relationships with other companies. Regarding environmental scanning, the integrator has focused on opportunities, researching new solutions and improvements for its services and management. The integrator has invested in IC, with greater focus on human and relational capital, highlighting the role of the staff in performing strategic analyses.

The MNOs have also invested in $\mathrm{KM}$, and have focused on market trends and end users' needs. This procedure corroborates one of the ideas of the new service-oriented value chain mode of telecom MVAS proposed by Tan and Zeng (2009). Their proposal highlighted that developing and providing telecom business will be based on users' practical demands in an information society rather than on existing network features. Therefore, the differential in this market lies in services that add value to the end user.

Regarding challenges in the national MVAS sector, the MNO respondents agree that the possibility of direct connection between content providers and MNOs threatens the integrator's role. However, this research shows that the integrator has observed market changes that justify the expansion of its commercial sector to improve communication with partners, the actions to turn IT into a more proactive and communicative sector, the search for new solutions, and the continuous scanning of the partners' actions.

The app stores imply a decrease in the number of MVAS end users but amplify mobile Internet use, thus increasing the sale of plans by the MNOs. The MNO respondents highlighted that primary challenges for their businesses included the development of more useful services and the competition. However, according to Teleco (2015), although the MVNOs represent a potential risk of loss of direct customers by MNO, the association with an MVNO can result in increased revenue and lower cost to customers. Regarding OTTPs, many analysts believe MNOs need to reinvent themselves as significant players in the over-the-top segment or risk losing a growth opportunity and becoming mere bandwidth providers.

This market has worked as an ecosystem with exchange of strategic information between the stakeholders. A business ecosystem is a complex networked system in which a variety of firms coexists in an interdependent and symbiotic relationship (Basole, 2008). Therefore, it is necessary to share the information so that the $\mathrm{Cl}$ system works (Kahaner, 1996). The collaboration is an important factor for emerging economies for innovation propensity (Temel, Mention and Torkkeli, 20I3). Jing and Xiong-Jian (20II) also observed

ISSN: 07 I8-2724. (http://www.jotmi.org) 
collaborative relationships in their study about the Chinese mobile telephone market. Although the Chinese market is different from that in Brazil, they concluded that the cooperation with partners has been a good opportunity to create a win-win situation in this business. These results are consistent with Luo's (2004) study that suggests the concept of coopetition.

\section{Final considerations}

The results show that devices with an Internet connection, app stores, MVNOs, and other innovations and changes in the mobile telephone market represent not only a risk but also an opportunity to MNOs, such as the investment in the MVAS production to increase their ARPU. In this context, the integrator has operated as a business enabler, creating market behavior indices and $\mathrm{Cl}$ to help other stakeholders in the decision-making.

The integrator has invested in KM and IC, developing IT systems, environmental scanning, and analyses regarding market trends to help its partners and to secure its role in this sector. Therefore, the results show the analysis of the collected data has been more relevant than the capacity of the integration platform.

This study was limited in several ways, including the small sample size that only focused on the market in Brazil. Regardless of these limitations, the current findings have added to our understanding of the Brazilian MVAS ecosystem, suggesting its dynamism, its focus on opportunities and innovation, and the coopetition between its stakeholders.

\section{Acknowledgements}

We would like to thank the Coordination for the Improvement of Higher Level Education Personnel (CAPES) for the PhD scholarship. It has allowed us to develop a research project about the mobile telephone market in Brazil. We would also like to thank Fernando Dias for his contribution to the development of this study.

\section{References}

BASOLE, R. C. (2008).Visualization of interfirm relations in a converging mobile ecosystem. 7th International Conference on Mobile Business - IEEE Computer Society, 65-74. doi: I0.1 I09/ICMB.2008.32

BIBOLINI, L., Lancaster, H. (20I4). Latin America - Telecoms, Mobile and Broadband Overview. I led.

CALOF, J.L. (2008). Selling competitive intelligence. Competitive Intelligence Magazine, I I (I), 39-42.

CHOO, C.W. (1999). The art of scanning the environment. Bulletin of the American Society for Information Science, 25(3), 2I-24. doi: 10. I002/bult. II 7

DUARTE, J. (2005). Entrevista em profundidade. In: Duarte, J., Barros, A. (Orgs). Métodos e técnicas de pesquisa em comunicação, led.Atlas, São Paulo. pp. 62-83.

ERICKSON, G.S., Rothberg, H. N. (2009). Intellectual capital in business-to-business markets. Industrial Marketing Management, 38(2), 159-165. doi: 10.1016/j. indmarman.2008.12.00I

FAHEY, L. (2007). Connecting strategy and competitive intelligence: refocusing intelligence to produce critical strategy inputs. Strategy \& Leadership, 35(I), 4-12. doi: I0.1108/108785707/07/7236

FRATTINI, F., Dell'Era, C., Rangone, A. (20/3). Launch decisions and the early market survival of innovations: an empirical analysis of the Italian mobile value-added services (VAS) industry. Journal of Product Innovation Management, 30(SI), I74-187. doi: 10.1 I I I/jpim. 12070

FRIES, F. H. (20I I). Estudo do Mercado de valor de serviço agregado de Telefonia Móvel. Bacharelado em Administração, UFRGS.

GODOY,A.S. (2006). Estudo de caso qualitativo. In: Godoi, C. K., Bandeira-de-Melo, R., Silva,A. B. (Eds). Pesquisa qualitativa em estudos organizacionais: paradigmas, estratégias e métodos, led. Saraiva, São Paulo. pp. I I5-I 45.

GSMA Intelligence. (20I4). The mobile economy 2014.

GSMA,ATKearney. (2013). The mobile economy 2013.

GSMA Intelligence, and The Boston Consulting Group (BCG). (20I3). Mobile economy Latin America 2013. 
GSMA mWomen, Cherie Blair Foundation for Women, ExxonMobil Foundation, and Booz \& Company UK. (20I2). Mobile value added services: a business growth opportunity for women entrepreneurs.

GUEGUEN, G., Isckia, T. (20II). The borders of mobile handset ecosystems: Is coopetition inevitable? Telematics and Informatics, 28, 5-I I. doi: 10.10 I6/j.tele.2010.05.007

HEINRICHS, J. H., Lim, J. S. (2005). Model for organizational knowledge creation and strategic use of information. Journal of the American Society for Information Science and Technology, 56(6), 620-629. doi: I0.1002/asi.20I52.

HEINRICHS, J.H., Lim, J. S. (2003). Integrating web-based data mining tools with business models for knowledge management. Decision Support Systems, 35(I), 103-I I 2. doi: 10.1016/S0167-9236(02)00098-2

JING, Z., Xiong-Jian, L. (20I I). Business ecosystem strategies of mobile network operators in the $3 \mathrm{G}$ era: the case of China Mobile. Telecommunications Policy, 35(2), |56-|7|. doi: 10.1016/j.telpol.2010.12.009

KAHANER, L. (1996). Competitive intelligence: how to gather, analyze, and use information on move your business to the top. Simon \& Schuster, New York.

LGT - Lei geral das telecomunicações. (1997). Law number 9.472 of July $16,1997$.

LOU, Y. (2004). Coopetition in international business. Copenhagen Business School Press, Denmark.

MACHADO, C. R., Abreu, A. F., Neto, M. A. (20I3). Best Practices in Brazilian Companies. Journal of Technology Management \& Innovation, 8, 79-9I. doi: 10.4067/S07/827242013000300007

MYLONOPOULOS, N. A., Sideris, I. A. (2006). Eletronic Markets, I6(I), 28-40.

PURE Bros. (2012). Doing mobile business in Brazil - How to set up or make your business profitable using mobile technologies through cell phones in Brazil. São Paulo: Issu.

SILVEIRA, A. B. (2008). Os processos da estratégia de inovação na cadeia de valor do setor de telefonia móvel. Negócios e Talentos, 5(5).

STEWART,T.A. (200I). The wealth of knowledge: Intellectual capital and the twenty-first century organization. Nicholas Brealey, London.
TAKEUCHI, H., Nonaka, I. (2008). Knowledge Management. Translate by Ana Thorell. Bookman, Porto Alegre.

TAN, Y., Zeng, J. (2009). Study on value chain of telecom VAS under transformation background. Communications and Network, I (2), 63-67. doi: 10.4236/cn.2009. 12010

TELECO intelligence in telecommunications. (2015).

TEMEL, S., Mention, A., Torkkeli, M. (2013). The Impact of Cooperation on Firms' Innovation Propensity in Emerging Economies. Journal of Technology Management \& Innovation, 8(I), 54-64. doi: $10.4067 /$ S07I8-272420I3000I00006

YIN, R. (2005). Estudo de caso: planejamento e métodos, 3ed. Bookman, Porto Alegre. 